\title{
ENRAIZAMENTO E CRESCIMENTO DE ESTACAS HERBÁCEAS DO CACAUEIRO (CLONES CEPEC 42, TSH 516 E TSH 1188) EM FUNÇÃO DA APLICAÇÃ̃O DO ÁCIDO INDOLBUTÍRICO (AIB) ${ }^{1}$
}

\author{
JOSÉ CLÁUDIO FARIA² \& CÉLIO KERSUL DO SACRAMENTO³
}

\begin{abstract}
RESUMO - Estacas apicais herbáceas de ramos plagiotrópicos do cacaueiro (clones CEPEC 42, TSH 516 e TSH 1188) foram tratadas com 0 e 6.000 mg.kg-1 do ácido indolbutírico (AIB) e estaqueadas em tubetes de $288 \mathrm{~cm}^{3}$ contendo como substrato uma mistura de Plantmax ${ }^{\circledR}$ e fibra de coco triturada (1:1), enriquecido com Osmocote ${ }^{\circledR}$ (19-06-20) e PG mix ${ }^{\circledR}$ (14-16-18). Os tubetes foram acondicionados em bandejas e estas foram mantidas em câmaras de nebulização. Na avaliação, realizada aos 78 dias após o estaqueamento, verificou-se que, independentemente da aplicação de AIB, as estacas dos clones avaliados apresentaram índices de enraizamento superiores a 87\%, mas o tratamento das estacas com AIB aumentou os índices de sobrevivência e de estacas enraizadas de todos os clones, número de raízes (clones TSH 516 e TSH 1188), matéria seca de raízes (Clones CEPEC 42 e TSH 516 ) e matéria seca da parte aérea (Clones TSH 566 e TSH 1188).
\end{abstract}

Termos para indexação: Theobroma cacao, propagação, estaquia.

\section{ROOTING AND GROWTH OF CACAO TREE CUTTINGS (CLONES CEPEC 42, TSH 516 AND TSH 1188 ) TREATED WITH INDOLBUTYRIC ACID (IBA)}

\begin{abstract}
Herbaceous cuttings of plagiotropic branches of cacao tree (clones CEPEC 42, TSH 516 and TSH 1188) were treated with 0 or $6,000 \mathrm{mg} \cdot \mathrm{kg}^{-1}$ of indolbutyric acid (IBA) and placed in small pots of $288 \mathrm{~cm}^{3}$ containing a mixture of Plantmax ${ }^{\circledR}+$ triturated coconut fiber $(1: 1)$, enriched with Osmocote ${ }^{\circledR}$ (19-06-20) and PG mix $^{\circledR}$ (14-16-18). The pots were kept in a chamber equipped with an intermittent misting system. The evaluation was carried out 78 days after striking, and it was verified an increasing of $87 \%$ of the cutting rooted for all clones tested, regardless of the IBA treatment. The IBA treatment increased the survival and rooting indices of all clones, as well as the numbers of roots (clones TSH 516 and TSH 1188), root dry weight (clones CEPEC 42 and TSH 516) and shoot dry weight (clones TSH 516 and TSH 1188).
\end{abstract}

Index terms: Theobroma cacao, propagation, cutting.

O cacaueiro (Theobroma cacao L.) é a principal planta cultivada no Sul da Bahia, ocupando uma área de cerca de $600 \mathrm{mil}$ ha em aproximadamente 30 mil propriedades. De acordo com Souza e Dias (2001), no Brasil, a cadeia produtiva do cacau envolve, atualmente, investimentos da ordem de 2,3 bilhões de reais; é responsável por aproximadamente três milhões de empregos e, destes, algo em torno de 300 mil diretos.

$\mathrm{Na}$ cacauicultura, a estaquia, como método de propagação vegetativa, é conhecida desde a década de 40 (Pike, 1933) e, segundo Purseglove (1968), foi utilizada em escala comercial em Trinidad nas décadas de 30 e 40 . Entretanto, com o lançamento de híbridos biclonais, no final da década de 50, o plantio clonal foi suplantado pela reprodução seminal. Com a disseminação da vassoura-de-bruxa (Crinipellis perniciosa (Stahel) Singer) na região Sul da Bahia, a partir de 1989, tornou-se estratégica a substituição de cacaueiros suscetíveis, de origem seminal, por plantas tolerantes, propagadas vegetativamente pelos métodos de enxertia e estaquia.

A estaquia dos clones de cacaueiro tolerantes, lançados pela pesquisa, foi estudada por Sena-Gomes et al. (1998) utilizando estacas herbáceas e semilenhosas de ramos plagiotrópicos, nas concentrações de $4.000,6.000$ e $8.000 \mathrm{mg} \mathrm{kg}^{-1}$ do ácido indolbutírico (AIB), tendo obtido índices de enraizamento superiores a $70 \%$ para os clones CEPEC 42 , TSH 516 e TSH 565 e inferiores a 55\% para o clone TSH 1188.

De acordo com Hall (1963), citado por Pereira (2001), a maioria das seleções de cacaueiro Forasteiros Amazônicos enraíza facilmente (em torno de 90\%), enquanto os genótipos Crioulos apresentam em torno de 60 a $70 \%$ de enraizamento.

Na Biofábrica de Cacau, localizada em Ilhéus - BA, mais de 15.000 estacas de cacaueiro são colocadas diariamente para enraizar, utilizando-se da concentração única de $6.000 \mathrm{mg} \cdot \mathrm{kg}^{-1}$ de AIB. Objetivando uma possível redução dos custos de produção das mudas, avaliaram-se o enraizamento e o crescimento inicial de estacas herbáceas dos clones CEPEC 42, TSH 516 e TSH 1188 submetidas às concentrações de $0 \mathrm{e}$ $6.000 \mathrm{mg} \cdot \mathrm{kg}^{-1} \mathrm{de}$ AIB.

O experimento foi conduzido em câmara de nebulização intermitente da Biofábrica de Cacau (BC), Ilhéus-BA, durante o período de

\section{0-03-2001 a 06-06-2001.}

Foram coletados ramos apicais plagiotrópicos com $30 \mathrm{~cm}$ de comprimento, em cacaueiros de 4 anos de idade, dos clones CEPEC 42, TSH 516 e TSH 1188, plantados no jardim clonal da BC. Após o corte, os ramos foram transportados para o galpão da Biofábrica, onde as estacas apicais herbáceas foram preparadas, ficando com o tamanho final de 16 $\mathrm{cm}$ de comprimento, $3 \mathrm{~mm}$ de diâmetro basal e com 3 folhas reduzidas à metade. Após o preparo as estacas tiveram suas bases tratadas com $0 \mathrm{ou}$ 6.000 mg. $\mathrm{kg}^{-1}$ de AIB em mistura com talco. A seguir, foram fincadas em tubetes de $288 \mathrm{~cm}^{3}$ contendo o substrato constituído da mistura de Plantmax ${ }^{\circledR}$ e fibra de coco triturada, na proporção 1:1, enriquecida com Osmocote $^{\circledR}$ (19-06-20) e PGmix ${ }^{\circledR}$ (14-16-18), na proporção de $300 \mathrm{~g}$ de cada produto para 120 litros do substrato. A seguir, as estacas foram colocadas em bandejas de 54 células e estas foram transferidas para as câmaras de nebulização com luminosidade de $50 \%$, equipadas com microaspersores em regime de 30 segundos de aspersão a cada 5 minutos, durante os 60 dias iniciais, e posteriormente em regime de 30 segundos de aspersão a cada 10 minutos, durante 7 dias, seguido por 20 segundos de aspersão cada 20 minutos, até a fase final. Durante a coleta, preparo e estaqueamento, as estacas foram freqüentemente aspergidas com água para evitar a desidratação. $\mathrm{O}$ experimento fatorial 3 clones (CEPEC 42, TSH 516 e TSH 1188) x 2 doses (0 e 6.000mg.kg-1 de AIB) foi montado no delineamento inteiramente casualizado, com 6 repetições e 9 estacas por unidade experimental.

Aos 78 dias após o estaqueamento, foram avaliados o índice de estacas sobreviventes (IS), razão percentual entre o número de estacas que sobreviveram e o número total de estacas, e o índice de enraizamento (IE), razão percentual entre o número de estacas que enraizaram e o número total de estacas, e, em cada unidade experimental, foram coletadas três plantas para avaliação do número de raízes de primeira ordem (NR), matéria seca das raízes (MSR) e da parte aérea (MSA). As raízes e a parte aérea - folhas e brotos emitidos após o estaqueamento - foram removidas das estacas, acondicionadas em sacos de papel e postas para secar em estufa de ventilação forçada, a $78^{\circ} \mathrm{C}$, até peso constante. Os dados do IS e do IE necessitaram passar pela transforma-

\footnotetext{
${ }^{1}$ (Trabalho 113/2002). Recebido: 11/06/2002. Aceito para publicação: 09/04/2003.

${ }^{2}$ Eng. Agr. Dr. Professor. Universidade Estadual de Santa Cruz, DCET, 45.650-000, Ilhéus-BA. Email: jcfaria@uesc.br.

${ }^{3}$ Eng. Agr. Dr. Professor. Universidade Estadual de Santa Cruz, DCAA, 45.650-000, Ilhéus-BA. Email: kersul@uesc.br.
} 
ção em arco-seno da raiz quadrada, e os demais pela transformação em raiz quadrada, para atender aos pressupostos da análise de variância. Os dados foram submetidos à análise de variância no esquema fatorial, efetuando-se as comparações entre clones, dentro de cada dose de AIB, assim como entre dose de AIB, dentro de cada clone, via contrastes.

O término do experimento aos 78 dias, quando o prazo médio da BC para liberação das mudas para o plantio é de 90 a 120 dias, foi estipulado a partir da observação contínua do desenvolvimento das unidades experimentais. Verificou-se a necessidade, em caso de aumento nesse prazo, de adubações de cobertura, consideradas fontes de variação não desejáveis aos objetivos originais do estudo.

Durante o período de condução do experimento, entre março e junho de 2001 , a temperatura média variou de 25,0 a $24,0^{\circ} \mathrm{C}$. Os resultados da avaliação, aos 78 dias de estaqueamento, são apresentados na Figura 1. O índice de sobrevivência (IS) (Figura 1a) de todos os tratamentos foi superior a 87 \% e, em relação à dose zero, a aplicação de 6.000 mg.kg-1 aumentou o IS dos clones TSH 516 e TSH 1188, e o clone CEPEC 42 não foi influenciado pela dose de AIB. Dentro dos níveis de AIB, não foi verificada diferença entre os clones. Observou-se que todas as estacas sobreviventes haviam emitido raízes. Os índices de enraizamento (IE) (Figura 1b), para todos os clones, foram superiores nos tratamentos com 6.000 mg. $\mathrm{kg}^{-1}$ quando comparados aos da dose zero, não tendo sido observadas diferenças entre clones dentro dos níveis de AIB. As estacas sem AIB apresentaram valores superiores a 87\%, corroborando a elevada capacidade de enraizamento do cacaueiro relatada por Hall (1963), citado por Pereira (2001) e Sacramento et al. (2001), que observaram a emissão de raízes em cacaueiro (clone 1188) a partir de 30 a 40 dias após o estaqueamento. Os IEs obtidos no presente trabalho foram superiores aos relatados por Sena-Gomes et al. (1998) os quais, trabalhando com estacas semi-lenhosas de cacaueiro tratadas com AIB, nas concentrações de 4.000 a 8.000 mg. $\mathrm{kg}^{-1}$, encontraram $76,7 \% ; 86,7 \%$ e $55 \%$ para os clones CEPEC 42, TSH 516 e TSH 1188, respectivamente. Vários fatores podem contribuir para o aumento da percentagem de enraizamento de estacas, incluindo a consistência da estaca, época de coleta, cuidados durante o preparo da estaca e tempo entre coleta da estaca e o estaqueamento. É provável que o tipo de estaca utilizada neste trabalho (apicais herbáceas) propicie melhores resultados no enraizamento que as semilenhosas utilizadas por Sena-Gomes et al. (1998). Conforme Hartmann et al. (1990), em plantas perenes, existe a possibilidade de escolha da estaca a ser utilizada para a propagação e que a capacidade de enraizamento, quanto à consistência do ramo, varia de acordo com cada espécie. Dentro dos níveis de AIB, a igualdade entre os clones quanto ao IS e ao IE pode ser atribuída à origem comum - possuem como um dos ascendentes o Scavina 6 (SCA 6).

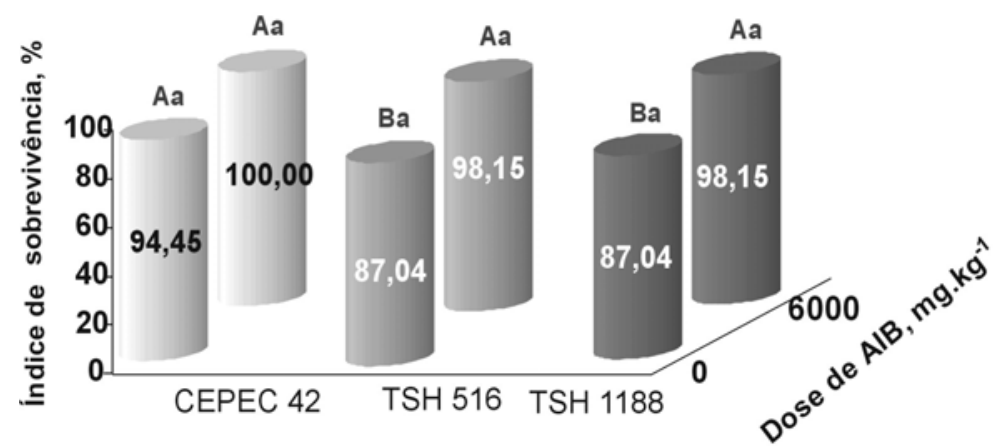

a) Índice de sobrevivência (IS), \% $\mathrm{cv}=12,84 \%$

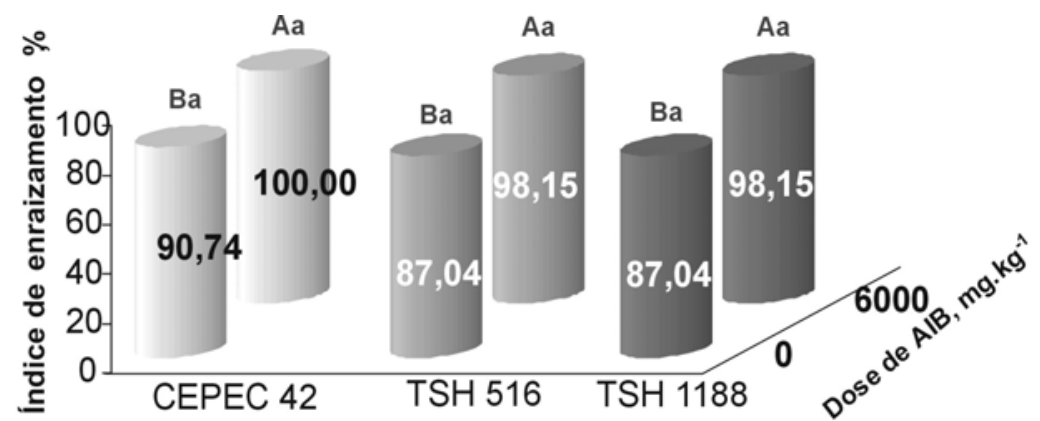

b) índice de enraizamento (IE), \% $\mathrm{cv}=12,51 \%$

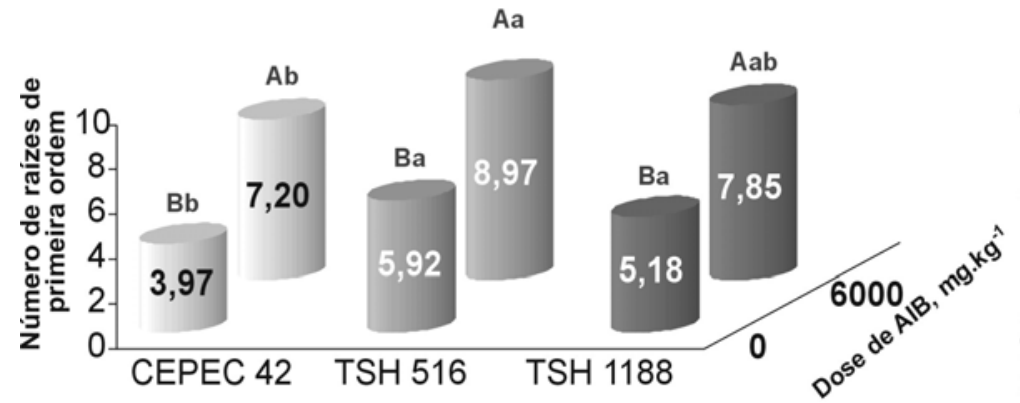

c) Número de raízes de primeira ordem (NR) $\mathrm{cv}=9,62 \%$

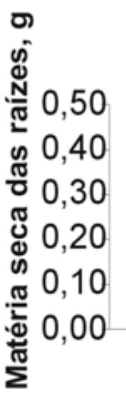

d) Matéria seca das raízes (MSR), g $\mathrm{cv}=9,80 \%$

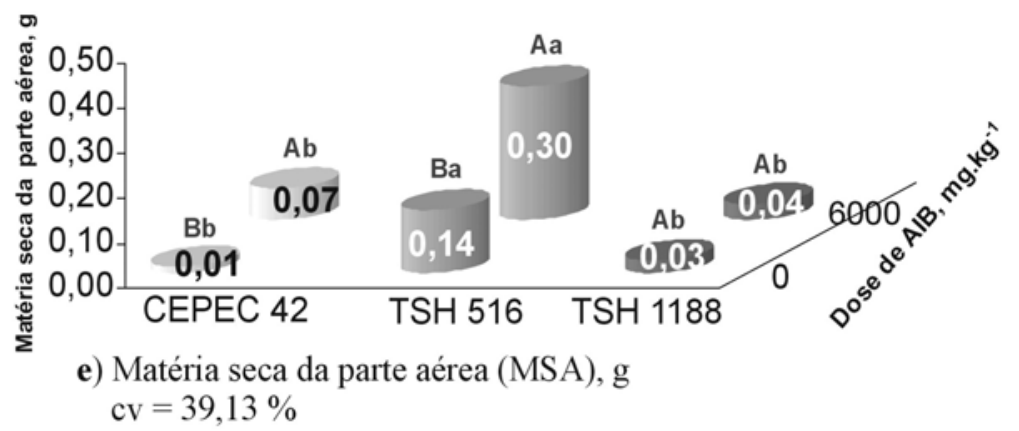

FIGURA 1- Enraizamento e crescimento inicial das estacas do cacaueiro (clones CEPEC 42, TSH 516 e TSH 1188 ) em função das doses zero e 6.000 mg. $\mathrm{kg}^{-1}$ do ácido indolbutírico (AIB). As letras em maiúsculo indicam as comparações das doses de AIB em cada clone. As letras em minúsculo indicam as comparações dos clones em cada dose de AIB. As médias seguidas de pelo menos uma mesma letra em comum não diferem entre si, ao nível de $5 \%$ de probabilidade, pelo teste $\mathrm{F}$. 
As estacas tratadas com AIB apresentaram média de raízes adventícias (NR) entre 7,2 e 9,0 (Figura 1c) e foram superiores, para todos os clones, às não tratadas, as quais apresentaram média entre 3,9 e 5,9 raízes por estaca. Na dose zero de AIB, o clone CEPEC 42 mostrouse inferior aos demais. $\mathrm{O}$ aumento do número de raízes em estacas tratadas com AIB, em comparação com as não tratadas, é reportado por vários autores (Hartmann et al., 1990; Nachtigal et al., 1999; Tonietto et al., 2001). Segundo Assis e Teixeira, citados por Tonietto et al. (2001), o AIB é um dos reguladores de crescimento mais utilizados para a indução de raízes, e o genótipo é um dos fatores que influenciam o enraizamento, existindo uma grande variação entre espécies, cultivares e clones em relação à maior ou menor habilidade natural em formar raízes.

Embora ainda não quantificada, tem sido observado pelos autores que a matéria seca das raízes (MSR) (Figura 1d) tende a estar mais bem correlacionada com a qualidade final das mudas que o NR, ou seja, quanto maior a MSR melhor a qualidade final da muda, possivelmente por estar a MSR, também, mais bem correlacionada com as áreas ativas de absorção de água e nutrientes. Observa-se que, em relação à dose zero, a MSR dos clones TSH 516 e TSH 1188 foi maior nas estacas tratadas com $6.000 \mathrm{mg} \cdot \mathrm{kg}^{-1}$. A matéria seca da parte aérea (MSA) (Figura 1e) dos clones CEPEC 42 e TSH 516 aumentou com a aplicação de AIB. Entre os clones estudados, o TSH 516 apresentou maiores valores da MSA, diferindo dos demais clones, independentemente da dose de AIB. Em trabalhos conduzidos por Sacramento et al. (2001) com estacas do cacaueiro clone TSH 1188, tratadas com AIB 6.000 mg. kg ${ }^{-1}$, verificou-se que a emissão de raízes teve início entre 20 e 30 dias, e o crescimento da parte aérea entre 60 e 70 dias após o estaqueamento. Portanto, a avaliação da MSA efetuada aos 78 dias de estaqueamento não fornece uma informação precisa dos efeitos dos tratamentos sobre essa variável.

Em função dos resultados observados, recomenda-se a aplicação do AIB nos clones estudados e sugere-se, como possível alternativa de redução de custos de produção da $\mathrm{BC}$, a otimização das doses de AIB para os clones multiplicados.

Nas condições em que foi realizado o experimento, pode-se concluir que:

a) Estacas apicais herbáceas do cacaueiro, clones CEPEC 42, TSH 516 e TSH 1188, apresentaram índices satisfatórios de sobrevivência e enraizamento, independentemente da aplicação da dose 0 ou $6.000 \mathrm{mg} \cdot \mathrm{kg}^{-1}$ do ácido indolbutírico (AIB).

b) Com exceção do índice de sobrevivência e matéria seca das raízes nas estacas do clone CEPEC 42, e matéria da parte aérea do clone TSH 1188 , a aplicação de $6.000 \mathrm{mg} \cdot \mathrm{kg}^{-1}$ de AIB provocou aumento em todas as variáveis avaliadas (índice de sobrevivência e enraizamento, número de raízes de primeira ordem, matéria seca das raízes e matéria seca da parte aérea) para todos os clones estudados.

\section{AGRADECIMENTOS}

Os autores agradecem aos Eng. Agr. José Carlos de Castro Macedo e Jesus Bahamonde Palácios, superintendente e gerente técnico, respectivamente, pela cessão das instalações e apoio, e a todos os funcionários do Instituto Biofábrica de Cacau, pela colaboração na execução deste trabalho, e ao prof. Eustáquio Marconcine Bini, pela correção do abstract.

\section{REFERÊNCIAS BIBLIOGRÁFICAS}

HARTMANN, H.T.; KESTER, D.E.; DAVIES JUNIOR, F.T. Plant propagation: principles and practices. 5.ed. New York:Englewood/PrenticeHall, 1990. 647p.

NACHTIGAL, J.C.; PEREIRA, F.M.; DALL'ORTO, F.A.C.; OJIMA, M.; MARTINS, F.P. Propagação vegetativa do umezeiro (Prunus mume) por meio de estacas herbáceas. Revista Brasileira de Fruticultura, Jaboticabal, SP., v.21, n.2, p. 226-228, 1999

PEREIRA, A.B. Melhoramento clonal In: Dias, L.A.S. (ed.) Melhoramento Genético do Cacaueiro, Viçosa: FUNARBE, 2001, p.361-384.

PIKE, E.E. The vegetative propagation of cacao. II. Softwood cuttings. Annual Report on Cacao Research n.2, p.3-9, 1933.

PURSEGLOVE, J.W. Tropical Crops: Dicotyledons 2. London, Longman, 1968, p.570-598.

SACRAMENTO, C.K.; FARIA, J.C.; PALÁCIOS, J.B.; CERQUEIRA, L.S. Enraizamento e crescimento de estacas de cacaueiro (clone TSH 1188) em função do tempo de estaqueamento. In: CONGRESSO BRASILEIRO DE FISIOLOGIA VEGETAL, 8º , 2001, Ilhéus, Anais...(CDRoom).

SENAGOMES,A.R.; CASTRO, GC.; MORENO-RUIZ,M.M.;ALMEIDA, H.A. Avanços na propagação clonal do cacaueiro no Sudeste da Bahia. In: PEREIRA, J.L. et al. (Ed) Atualização sobre Produção Massal de Propágulos de Cacau Geneticamente Melhorado, Atas, CEPEC: BA, Ilhéus, 1998. p.85-89.

SOUZA, C.A.S.; DIAS, L.A.S. Melhoramento ambiental e socioeconomia. In.: DIAS, L.A.S. (Ed.) Melhoramento genético do cacaueiro. Viçosa, FUNAPE, UFG, 2001. p.1-47.

TONIETTO, A.; FORTES, GR.L.; SILVA, J.B. Enraizamento de miniestacas de ameixeira. Revista Brasileira de Fruticultura, Jaboticabal-SP., v.23, n.2, p. 373-376, 2001 